\title{
Lymphangioma secondary to irradiation after mastectomy*
}

\author{
Aline Oliveti ${ }^{1}$ \\ Gabriella Di Giunta Funchal ${ }^{3}$
}

Tatiana Basso Biasi²

DOI: http://dx.doi.org/10.1590/abd1806-4841.20173952

\begin{abstract}
Lymphangioma is a rare benign disease of the lymphatic vessels. Typically, they are primary conditions but may be acquired secondarily, such as those caused by irradiation during radiotherapy for the treatment of breast cancer. The local lymphatic obstruction provoked by irradiation causes the appearance of asymptomatic hyaline vesicles on the irradiated skin. The present report describes a 78-year-old female patient, who initially presented hyaline vesicles that progressed into multiple papules with serous exudation of a yellowish and odorless secretion on the area of chronic radiodermitis in right breast. Despite the rarity of the case, we emphasize the importance of knowledge regarding dermatological disease for early diagnosis and proper medical conduct.
\end{abstract}

Keywords: Breast neoplasms; Lymphangioma; Mastectomy; Skin; Radiotherapy

\section{INTRODUCTION}

Lymphangiomas are rare benign lesions, usually congenital, wihich frequently affect the head, neck, and oral cavity regions. They represent approximately $6 \%$ of all benign lesions in children, and typically occur before the age of two. ${ }^{1}$ Lymphangiomas are analogous to hemangiomas, as they are formed by widely dilated lymphatic spaces, covered by endothelial cells, and separated by connective tissue stroma, associated with lymphoid aggregates. ${ }^{2}$

Although they are often primary conditions, lymphangiomas may be secondarily acquires, such as, after radiation therapy. ${ }^{3}$ Due to its rarity, this study describes the case of a 78-year-old female patient, who had been diagnosed with lymphangioma acquired as a late complication of radiation therapy for breast cancer treatment.

\section{CASE REPORT}

Female patient, caucasian, 78 years of age, born and growed in the city of Florianópolis.

In 2003, the patient was diagnosed with atypical medullary carcinoma, $2 \times 2 \mathrm{~cm}$, on the right breast, without lymphonodular metastasis. Quadrantectomy was performed, in association with radiation therapy and chemotherapy. In 2007, she was diagnosed with invasive ductal carcinoma on the left breast, with signs of blood and lymphatic invasion. Surgical therapy, with quadrantectomy associated with axillary node dissection, was selected.

Since 2005, she has been seeing a dermatologist annually, with several complaints, such as actinic keratosis, seborrheic keratosis, solar melanoses, and melanocytic nevus, among others.

The patient exhibits several comorbidities, such as high blood pressure, cardiac arrhythmia, hiatal hernia, depression, hypothyroidism, gastritis, diverticulitis, and hemorrhoids, all of which are being monitored. Patient currently takes sotalol chlorhydrate $150 \mathrm{mg}$, rosuvastatin $20 \mathrm{mg}$, omeprazole $40 \mathrm{mg}$, amlodipine besylate $20 \mathrm{mg}$, levothyroxine $75 \mathrm{mcg}$, hydrochlorothiazide $25 \mathrm{mg}$, and flunitrazepam $2 \mathrm{mg}$.

In October 2013, the patient noticed the occurrence of hyaline vesicles on the right breast, in the site where surgery and radiation therapy had been performed. She used topical mupirocin for 20 days, with no improvements to the symptoms. Her oncologist had instructed her to puncture the lesions. No other associated symptoms were observed. During her appointment, she needed to maintain dressings over the lesions, as there was constant exudation of an odorless, serous, yellowish secretion.

Received on 17.08.2014

Approved by the Advisory Board and accepted for publication on 09.04.2015

* Work conducted at a private clinic, Florianópolis, SC, Brazil.

Financial support: none.

Conflict of interest: none.

Medical Academy, Fundação Universidade Regional de Blumenau - Blumenau (SC) Brazil.

Private Clinic - Florianópolis (SC) Brazil.

Pathological Anatomy Service, Hospital Universitário Polydoro Ernani de São Thiago, Universidade Federal de Santa Catarina (HU-UFSC) - Florianópolis (SC) Brazil.

()217 by Anais Brasileiros de Dermatologia 
The dermatological examination identified the presence of multiple yellowish papules, approximately 1 to $3 \mathrm{~mm}$ in size, over chronic radiodermatitis area of the right breast (Figure 1). It was also possible to identify the presence of some papules with spontaneous drainage of yellowish solution (Figure 2). The affected area was restricted to irradiated region of the right breast.

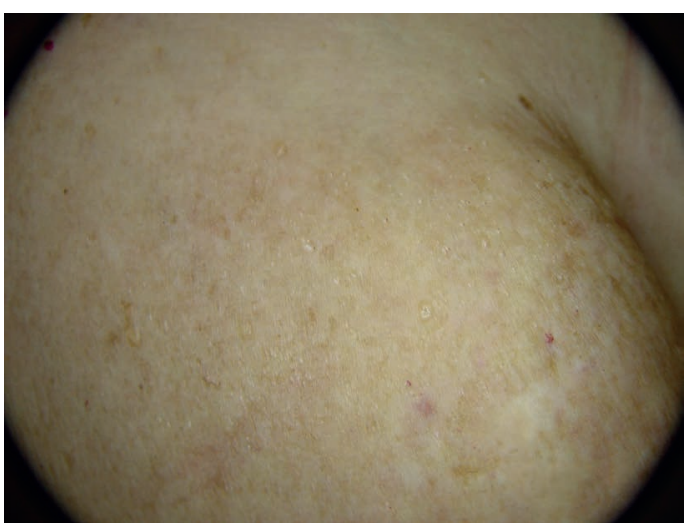

FIGURE 1: Right breast with the presence of multiple yellowish papules, approximately $1-3 \mathrm{~mm}$ in size, over the chronic radiodermatitis area

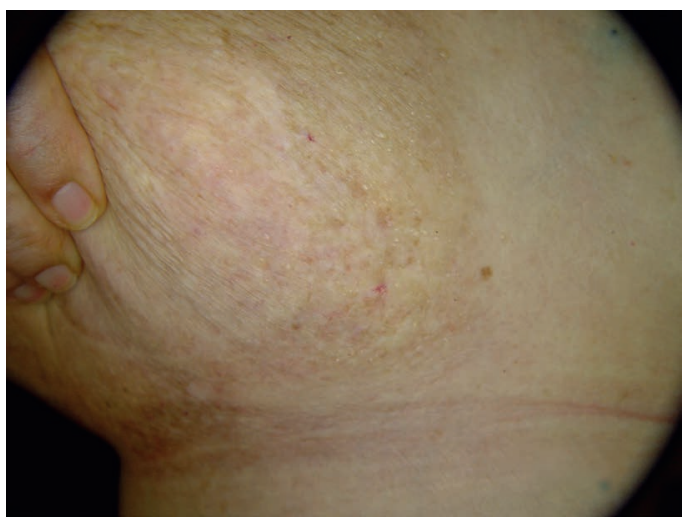

FIGURE 2: Right breast with the presence of multiple papules with spontaneous drainage of yellowish fluid

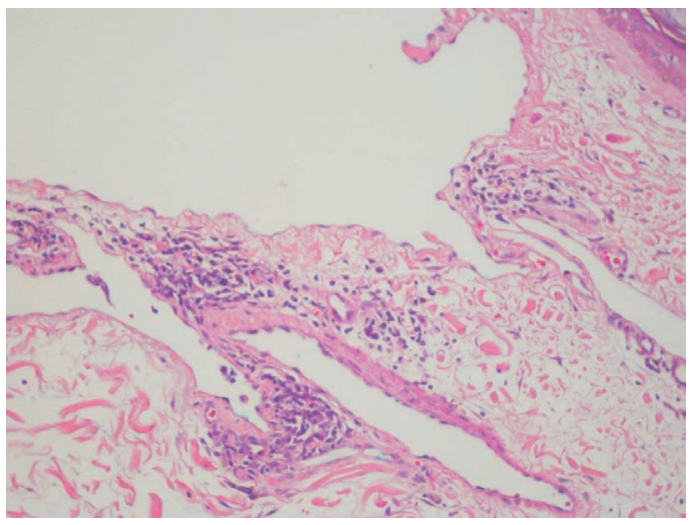

Figure 3: Hematoxylin-eosin stained slide showing dilated vascular spaces, of varied sizes, with ectatic lymphatic vessels surrounded by lymphocytes 200x

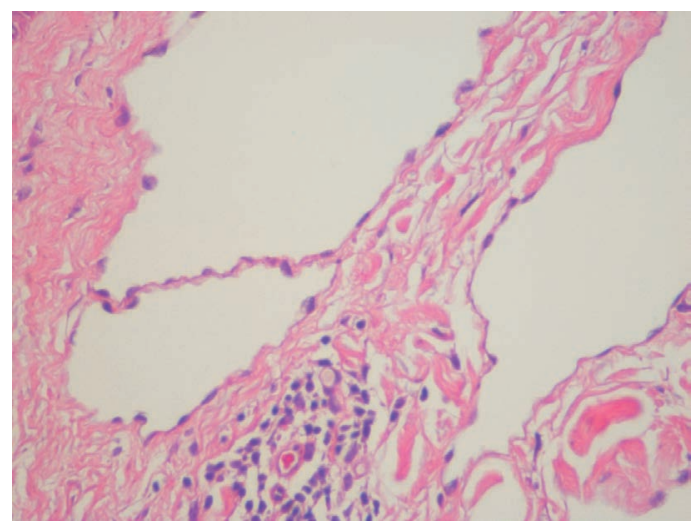

Figure 4: Hematoxylin-eosin stained slide showing dilated vascular spaces, of varied sizes, under higher magnification $400 x$

The initial clinical diagnostic impression was lymphangioma, although the possibility of localized hyperhidrosis was also considered. The biopsy revealed interconnected and ectatic lymphatic vessels on the papillary dermis, delimiting a cavity with serous content and lymphoid aggregates in the surrounding dermis, confirming the lymphangioma hypothesis (Figures 3 and 4).

\section{DISCUSSION}

Radiation therapy is a complementary breast cancer treatment following mastectomy. There are several guidelines regarding this therapy's indication, usually related to the extent of lymph node involvement. It is largely relevant in breast cancer treatment and has shown reductions in the neoplasia's locoregional recurrence and significant increase in survival rates. ${ }^{4}$

Despite its proven benefits, radiation therapy may also cause some alterations that affect adjacent structures, leading to tissue complications. Lesions caused by irradiation occur mainly in the junction between reticular dermis and fatty tissues, resulting in fibrosis, lymphatic obstruction, increased local pressure and, consequently, lymphatic fluid accumulation. Clinically, due to saccular dilatation of superficial lymphatic channels, lesions may vary from hyaline fluid vesicles to reddish nodules. Although radiation therapy induces several malignant proliferations on the skin, such as high grade angiosarcoma, acquired lymphangioma is a lesion with benign evolution, and its main complications include pain, cellulites, and vesicle overflow. ${ }^{5,6}$

Microscopic analysis in hematoxylin-eosin stained slide reveals ectatic lymphatic spaces on the papillary dermis, lined by normal endothelial cells, hyperkeratotic overlying epidermis, and infiltration of chronic inflammatory cells in the dermis. ${ }^{7}$ Plotinick et al., in 1956, reported the first case of lymphangioma secondary to mastectomy, and named the dilated lymphatic vessels as lymphangiectasias. ${ }^{8}$ A biopsy of the lesions is important both for diagnostic and therapeutic purposes. ${ }^{7}$

The most recently published case of lymphangioma acquired after radiation therapy for breast cancer was reported in 2013 by Baum et al. The patient described exhibited erythematous papules on the right breast, after four years of treatment including 
lobectomy and radiation therapy for ductal carcinoma in situ. As expected, lesion evolution was benign, without complications. ${ }^{9}$

In Brazilian medical literature, only one case of acquired lymphangioma has been described; however, this was found in a vulvar location, secondary to radiation therapy after uterine cancer treatment. This is considered the second case of lymphangioma acquired after radiation therapy in international literature, and was published in Anais Brasileiros de Dermatologia (ABD) in 1970. Translucent vesicular lesions occurred on the outer labia, on the previous irradiation focuses, after 14 years of the instituted therapy. Biopsy showed for revealing the presence of ectatic lymphatic vessels. ${ }^{10}$

Lymphangioma acquired after radiation therapy is characterized by the late onset of translucent vesicles in the irradiated location, as disease progression is insidious. Based on the clinical suspicion, the final diagnosis will be elucidated by the biopsy, which reveals typical aspects of ectasia and interconnection of lymphatic vessels and lymphoid aggregates. This is a rare condition, as few cases have been reported in international literature, and it may be considered the first case of lymphangioma acquired after breast radiation therapy described in Brazilian literature, in accordance with research performed on CAPES, Medline, and Pubmed databases. This condition should always be taken into account in the diagnosis of patients with vesicular lesions and a previous history of radiation therapy after tumor resection surgery. Unfamiliarity of this dermatological condition, both by dermatologists and oncologists, may delay the diagnosis of the disease, and lead to mistaken conducts, such as that which affected the patient described in this study. $\square$

\section{REFERENCES}

1. Orvidas LJ, Kasperbauer JL. Pediatric lymphangiomas of the head and neck. Ann Otol Rhinol Laryngol. 2000;109:411-21.

2. Kumar V, Abbas AK, Fausto N, Aster JA. Robbins e Cotran: Bases Patológicas das Doenças. 8. ed. Rio de Janeiro: Elsevier; 2010.

3. Coles CE, Moody AM, Wilson CB, Burnet NG. Reduction of radiotherapy-induced late complications in early breast cancer: the role of intensity-modulated radiation therapy and partiabreast irradiation. Part I-- normal tissue complications. Clin Oncol (R Coll Radiol). 2005;17:16-24.

4. Olivotto IA, Truong PT, Chua B. Postmasctectomy Radiation Therapy: Who Needs It? J Clin Oncol. 2004;22:4237-9.

5. Tasdelen I, Gokgoz S, Paksoy E, Yerci O, Cetintas SK, Demiray M, et al. Acquired lynphangiectasis after breast conservation treatment for breast cancer: report of a case. Dermatol Online J. 2004;10:9

6. Laskin WB, Silverman TA, Enzinger FM. Postradiation soft tissue sarcomas: An analysis of 53 cases. Cancer. 1988;62:2330-40.

7. Kaya TI, Kokturk A, Polat A, Tursen U, Ikizoglu G. A case of cutaneous lymphangiectasis secondary to breast cancer treatment. Int $\mathrm{J}$ Dermatol. 2001;40:760-1.

8. Plotinick $\mathrm{H}$, Richfield $\mathrm{D}$. Tuberous lymphangiectatic varices secondary to radical mastectomy. AMA Arch Derm. 1956;74:466-8.

9. Baum S, Patel R, McLellan B. A vascular growth following radiation therapy for breast carcinoma treatment: atypical vascular lesion (AVL) (lymphatic type). JAMA Dermatol. 2013;149:1341-2.

10. Sternick, M. Linfangioma Adquirido. An Bras Dermatol. 1971;46:61-4

\author{
MAILING ADDRESS: \\ Tatiana Basso Biasi \\ Av. Trompowsky, 291/903 - Centro \\ 88015-300 - Florianópolis - SC \\ Brazil \\ E-mail: tatiana@medicinadapele.com.br
}

How to cite this article: Oliveti A, Biasi TB, Di Giunta Funchal G. Lymphangioma secondary to irradiation after mastectomy. An Bras Dermatol. 2017;92(3):395-7. 